\title{
Symptom Experiences and Coping Strategies among Multi- ethnic Solid Tumor Patients Undergoing Chemotherapy in Malaysia
}

\author{
Nor Aziyan Yahaya ${ }^{1 *}$, Pathmawathi Subramanian ${ }^{1}$, Anita Zarina Bustam², Nur \\ Aishah Taib ${ }^{3}$
}

\begin{abstract}
Background: This study was performed to assess patient symptoms prevalence, frequency and severity, as well as distress and coping strategies used, and to identify the relationships between coping strategies and psychological and physical symptoms distress and demographic data of cancer patients. This cross-sectional descriptive study involved a total of 268 cancer patients with various types of cancer and chemotherapy identified in the oncology unit of an urban tertiary hospital. Materials and Methods: Data were collected using questionnaires (demographic questionnaire, Medical characteristics, Memorial Symptom Assessment Scale (MSAS) and Brief COPE scales and analyzed for demographic, and disease-related variable effects on symptom prevalence, severity, distress and coping strategies. Results: Symptom prevalence was relatively high and ranged from $14.9 \%$ for swelling of arms and legs to $88.1 \%$ for lack of energy. This latter was the highest rated symptom in the study. The level of distress was found to be low in three domains. Problem-focused coping strategies were found to be more commonly employed compared to emotion-focused strategies, demonstrating significant associations with sex, age group, educational levels and race. However, there was a positive correlation between emotion-focused strategies and physical and psychological distress, indicating that patients would choose emotion-focused strategies when symptom distress increased. Conclusions: These findings demonstrate that high symptom prevalence rates and coping strategies used render an improvement in current nursing management. Therefore development of symptoms management groups, encouraging the use of self-care diaries and enhancing the quality of psychooncology services provided are to be recommended.
\end{abstract}

Keywords: Symptoms - prevalence rates - cancer patients - chemotherapy - coping strategies

Asian Pac J Cancer Prev, 16 (2), 723-730

\section{Introduction}

Cancer is one of the main killer in the world and more than half a million people reported death in United States this year (Cancer Facts and Figures, 2014). Based on the latest Health Facts 2013 released by Ministry of Health $(\mathrm{MoH})$ Malaysia, cancer is one of the top ten causes of hospitalization and one of the top five causes of death in both $\mathrm{MoH}$ and private hospitals. The salient truth is that cancer has overtaken heart disease as the number one killer this year 2014 (Cancer Research Initiatives Foundation, 2014). Despite the issue, various treatments have been developed to improve patients' survival. The treatments produce a variety of side effects including intense physical and psychological symptoms, regardless of the stage of the disease which significantly increase psychological distress and alter patients' health-related quality of life (Tuncay and Isikhan, 2010; Dupuis et al.,
2012; Gunusen et al., 2013; Roy et al., 2014). Several studies have highlighted high prevalence rates of side effects during treatment (Walsh et al., 2000; Francoeur, 2005; Miaskowski et al., 2007). Physical problems were significantly associated with distress among Malaysian cancer patients, but little is known on the actual burden of symptoms while undergoing chemotherapy (Zainal et al., 2007; Saniah and Zainal, 2010). In addition, when the side-effects are not managed effectively, they can cause interruptions and delay cancer treatments (Weeks et al., 2012). Most significantly, it has been shown to reduce patient compliance to treatment, with an obvious impact on the prospect of surviving the disease (Jacobsen et al., 2007; Shoemaker et al., 2011). Recent findings in a study among Malaysian populations shows, about $34 \%$ of cancer patients' had defaulted treatment and do not complete chemotherapy because of severity side effects due to chemotherapy (Caryn Chan et al., 2014). 
Coping strategies employed whilst experiencing side effects during treatments have been an important oncology nursing research focus. Caution need to be taken when intervening as they may be ineffective and potentially harmful (Engvall et al., 2011). Psychological distress encompasses a series of negative emotions such as anxiety and depression, which are the end states of a maladaptive process (Zabalegui et al., 2005; Zainal et al., 2007; Saniah and Zainal, 2010). Few studies in Asia have looked at the symptom burden, coping mechanisms to assist in the development of an intervention programme. Cultural and lingusitic differences should also be taken into account as Malaysians are a heterogenous society. Therefore, this study aims to measure the symptom experiences, burden and coping strategies during chemotherapy according to demography and clinicopathological characteristics of Malaysian patients.

\section{Materials and Methods}

\section{Design and sample}

A cross-sectional survey using questionnaires was carried out over 6 months among adult solid tumor patients who were undergoing chemotherapy at an urban tertiary hospital. The population for this study comprises solid tumor patients. Sample size calculation for patients was based on confidence level cited at $95 \%$, margin of error plus or minus $5 \%$, with a population size of 1100 (Raosoft Sample Size Calculation, n.d). Since the population size is not large, the problem of committing type II error is small. Out of 285, 268 solid tumor patients who undergo chemotherapy participated in this study, where 10 patients did not participate due to myelosuppression and treatment interruption, 5 patients stopped treatment due to poor health, 2 patients had defaulted treatment during the period of data collection. A convienience sampling was chosen to get a good representation of the overall population in a study period of time (Currier, 1984). The eligible patients were identified through a list of patients from chemotherapy appointment diary and patients' medical records from 2010 to 2011 . The target population for this study were adult patients,aged 18 years and above with a solid tumor of any site. The inclusion criteria were patients must undergone at least one cycle of chemotherapy, has experienced side effects of chemotherapy and has no neurologic or psychiatric disorder.

\section{Ethical considerations}

Ethical approval was obtained from the hospital's Medical Ethics Committee.The purpose and the voluntary nature of the study were explained to them. Participants were reassured of the anonymity and confidentiality of their survey responses.

\section{Data collection and tools}

Patient's medical characteristics were obtained from medical records. These include cancer sites, disease stage, duration and regimen of chemotherapy, Eastern Cooperative Oncology Group (ECOG) performance status and other demographic features. Multidimensional
Memorial Symptom Assessment Scale (MSAS) and Brief COPE scales were used. Both instruments were translated into Malay language using back translation technique (Malay to English and English to Malay). For Malay version of MSAS, the Cronbach's alpha obtained in 32 items were 0.899 with sub-dimension of physical, $\alpha=0.838$ and sub-dimension psychological, $\alpha=0.575$ which was slightly higher than coefficient alpha reported for Chinese version of MSAS (Cheng et al., 2009). Whereas for Malay version of Brief COPE scale, the Cronbach's alpha ranged from 0.51 to 0.99 in 14 sub dimensions which are quite consistent with Cronbach's alpha reported by Yusoff et al. (2009).

Multidimensional Memorial Symptom Assessment Scale (MSAS) comprised of 32 items (26 physical and 6 psychological symptoms) to evaluates symptoms frequency, severity and distress by using a Likert Scale, the severity $(0=$ not at all to $4=$ very severe $)$, frequency $(0=$ not at all to $4=$ almost constantly), and distress ( $0=$ not at all to 4=very much). Twenty-four symptoms are evaluated with respect to frequency, intensity, and distress, and 8 symptoms are evaluated in terms of severity and distress only (mouth sores, change in the way food tastes, weight loss, constipation, hair loss, swelling of arms and legs, changes in skin, "I don't look like myself") (Portenoy et al., 1994). The scoring of the MSAS yields several subscale scores, including a Physical of High prevalence and Low prevalence Symptom subscale score (PHYS H and PHYS L), a Psychological Symptom subscale score (PSYCH), and a Global Distress Index (GDI). The PHYS H group is the average of the score for the 12 symptoms: lack of appetite, lack of energy, pain, feeling drowsy, constipation, dry mouth, nausea, vomiting, change in food taste, weight loss, feeling bloated, and dizziness. The L PHYS group is the average of the 14 symptoms: Numbness/tingling in hands/feet, hair loss, changes in skin, cough, "I don't look like myself", mouth sores, sweats, diarrhea, shortness of breath, itching, difficulty swallowing, problems with urination, problems with sexual interest or activity, and swelling of arms and legs. The PSYCH is the average of the score for the six symptoms: worrying, feeling sad, feeling nervous, difficulty sleeping, feeling irritable, and difficulty concentrating. Whereas the GDI is the average of the frequency of four psychological symptoms (feeling sad, worrying, feeling irritable, and feeling nervous) and the distress associated with six physical symptoms (lack of appetite, lack of energy, pain, feeling drowsy, constipation, dry mouth). The Total MSAS score (TMSAS) is the average of the symptom scores of all 32 symptoms in the MSAS. The validity and reliability of the English version of MSAS was tested using Cronbach's alpha test after the pilot study was conducted and ranging from 0.80 to 0.92 which was slightly higher than coefficient alpha reported by Cheng et al. (2009) and Portenoy et al. (1994).

Brief COPE scales is an instrument to identify coping strategies used by cancer patients to overcome the distress that occurred to them while undergoing chemotherapy. In health psychology, the COPE and the Brief COPE have predicted clinically relevant outcome across many stressful situations and populations (Horney et al., 2011; Dedert et al., 2012; Yoo et al., 2014; Tuncay, 2014). This 
Symptom Experiences and Coping Strategies among Multi-Ethnic Solid Tumor Patients Undergoing Chemotherapy in Malaysia

scale comprised of 14 dimensions (self-distraction, active coping, denial, substance use, use of emotional support, use of instrumental support, behavioral disengagement, positive reframing, planning, humor, acceptance, religion and self-blame) with 28 items (two items for every dimension) and rated by the four-point Likert scale, ranging from 1="I haven't been doing this at all" to 4="I have been doing this a lot" (Carver, 1997). The high the score indicated that the higher used of these coping strategies (Ben-Zur et al., 2001). The minimum score given was 2 and maximum score was 8 . For mean score interpretations was $2.00=$ haven't been doing this at all, 2.01 to $4.00=$ have been doing this a little bit, 4.01 to $6.00=$ have been doing this a medium amount, 6.01 to $8.00=$ have been doing this a lot (Carver, 1997). The coping strategies grouped into two major categories, problemfocused (religion, acceptance, use of emotional support, use of instrumental support, positive reframing, active coping, planning and humor) and emotion-focused (selfdistraction, venting, substances use, self-blame, denial and behavioral disengagement) (Ben-Zur et al., 2001). The English version of Brief COPE scale, the Cronbach's alpha of 0.789 and in 14 sub dimensions ranging from 0.56 to 0.98 obtained are quite consistent with Cronbach's alpha reported by Yusoff et al. (2009).

\section{Statistical analysis}

Data were recorded and analyzed using SPSS version 16. Demographic and medical characteristics were analyzed using descriptive statistics such as frequency, percentage, mean and mode difference for symptoms frequency, severity and distress. An Independent t-test and ANOVA test analysis were used to determine an association between demographics and coping strategies. Pearson's $r$ correlation coefficient test was used to determine whether there is a relationship between specific coping strategies and symptom distress among the study population.

\section{Results}

\section{Demographic and medical characteristics}

The socio demographic and medical characteristics of the patient are summarized in Table 1. The mean age of the respondents were 53.4 \pm 12.2 , ranging from the youngest at 19 years old to the oldest at 81 years old. The majority were female $(78.7 \%)$, married $(83.6 \%)$ and of Chinese ethnicity (64.9\%); had secondary education as the highest level of education (45.9\%); were unemployed (73.5\%); had good performance status (ECOG 0-1,79.9\%) and had non-metastatic cancers (Stage I-III, 63\%); were treated with curative intent (neoadjuvant /adjuvant, 64.2\%) and had combination chemotherapy $(67.1 \%)$. In descending order of frequency, almost half of the patients had breast cancer followed by colorectal, gynecological cancer, lung, head and neck cancers, and others.

\section{Symptom characteristics}

In Table 2, symptoms prevalence ranged from $88.1 \%$ for fatigue to $14.9 \%$ for swelling of arms and legs. The 10 other most prevalent symptoms besides fatigue were dry mouth $(75 \%)$, hair loss $(67.9 \%)$, feeling drowsy $(67.2 \%)$, lack of appetite $(60.1 \%)$, difficulty in sleeping $(58.2 \%)$, nausea $(58.2 \%)$, change in the way food tastes $(56 \%)$, worrying $(51.9 \%)$, pain $(51.1 \%)$ and feeling $\operatorname{sad}(50.7 \%)$. Examination of mean frequency scores showed that lack of appetite (2.60), lack of energy (2.50), problems with urination $(2.50)$, problems with sexual interest (2.50), feeling drowsy (2.50), dry mouth (2.40), difficulty sleeping (2.40), feeling bloated (2.30), difficulty in swallowing (2.30) and vomiting (2.20) were symptoms that occurred most often. Symptoms rated most severe were hair loss (2.90), "I don't look like myself" (2.30), difficulty in sleeping (2.20), vomiting (2.20), change in the way food tastes (2.20), lack of appetite (2.20), lack of energy (2.10), mouth sores (2.10), constipation (2.10), and problems with sexual activity (2.10). The symptoms causing most distress were lack of energy (1.80), hair loss (1.30), lack of appetite (1.30), difficulty in sleeping (1.20), dry mouth (1.20), feeling drowsy (1.10), and change in the way food tastes (1.10) and pain (1.10). The total mean score for psychological group was $5.47 \pm 4.9$. In the high prevalence symptoms distress group, the total mean score was $12.4 \pm 7.9$. Whereas in the low prevalence symptoms distress group, the total mean score was $8.67 \pm 6.3$.

Association between ECOG performance index with psychological distress and physical symptom distress

In this study, only one variable in demographic characteristics showed a statistically significant association with psychological distress and physical symptom distress, which is the ECOG performance status. For psychological distress, a two-way contingency analysis of Fisher's Exact test showed that the difference in the proportions was statistically significant, $\chi^{2}(1, \mathrm{~N}=268)=9.145, \mathrm{P}<0.05$, phi Coefficient $=0.185(\mathrm{p}=0.002)$. The proportion of low and high psychological distress appeared significantly higher than low and high psychological distress in poor performance status $(>1)$. Logistic regression was conducted between two groups of performance status $(<1$ $v s \geq 1$ ). At $\mathrm{P}$-value $<0.05$, the odds of high psychological distress in respondents with good performance status was 2.5 (95\% CI: 1.3 to 4.6 ) times higher than patients in poor performance status. Meanwhile for physical distress, the difference in the proportions was statistically significant, $\chi^{2}(1, \mathrm{~N}=268)=6.046, \mathrm{p}<0.05$, phi Coefficient $=0.150$ $(\mathrm{p}=0.014)$. The proportion of low and high physical distress appeared significantly higher than low and high physical distress in poor performance status $(>1)$. Logistic regression was conducted between two groups of performance status $(<1 v s \geq 1)$. At $\mathrm{P}$-value $<0.05$, the odds of high physical distress in respondents with good performance status was 2.1 (95\%CI: 1.1 to 3.8) times higher than patients in poor performance status.

\section{Coping strategies used by patients}

The coping strategies used are presented in Table 3. Analysis indicated that the most common coping strategies used by respondents were "Religion" with a mean of $6.5 \pm 1.8$, followed by "Acceptance" $(6.4 \pm 1.6)$, "Use of emotional support" $(6.3 \pm 1.7)$, "Use of instrumental

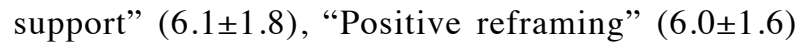




\begin{tabular}{|c|c|c|c|}
\hline Characteristic & & \multicolumn{2}{|c|}{$\mathrm{n} \quad \%$} \\
\hline Age $($ mean $\pm \mathrm{SD})$ & & Range from $19-81$ &, $53.44 \pm 12.1$ years \\
\hline \multirow[t]{5}{*}{ Age group } & $<35$ & 26 & 9.7 \\
\hline & $36-45$ & 32 & 11.9 \\
\hline & $46-55$ & 91 & 34.0 \\
\hline & $56-65$ & 74 & 27.6 \\
\hline & $>66$ & 45 & 16.8 \\
\hline \multirow[t]{2}{*}{ Sex } & Male & 57 & 21.3 \\
\hline & Female & 211 & 78.7 \\
\hline \multirow[t]{3}{*}{ Marital status } & Single & 27 & 10.1 \\
\hline & Married & 224 & 83.6 \\
\hline & Others & 17 & 6.3 \\
\hline \multirow[t]{4}{*}{ Ethnic Group } & Malay & 59 & 22.0 \\
\hline & Chinese & 174 & 64.9 \\
\hline & Indian & 30 & 11.2 \\
\hline & Others -Eurasian & 5 & 1.9 \\
\hline \multirow[t]{5}{*}{ Education Levels } & No formal education & 13 & 4.9 \\
\hline & Primary school & 68 & 25.4 \\
\hline & Secondary school & 123 & 45.9 \\
\hline & College/Institute & 31 & 11.6 \\
\hline & University & 33 & 12.3 \\
\hline \multirow{2}{*}{ Employment Status } & Employed & 71 & 26.5 \\
\hline & Not employed/housewife/retiree & 197 & 73.5 \\
\hline \multirow[t]{4}{*}{ ECOG Performance status } & 0 & 94 & 35.1 \\
\hline & 1 & 120 & 44.8 \\
\hline & 2 & 42 & 15.7 \\
\hline & 3 & 12 & 4.5 \\
\hline \multirow[t]{6}{*}{ Cancer sites } & Breast & 131 & 48.9 \\
\hline & Colorectal & 49 & 18.3 \\
\hline & Lung & 21 & 7.8 \\
\hline & Head and Neck & 17 & 6.3 \\
\hline & Gynecology & 27 & 10.1 \\
\hline & Others & 23 & 8.6 \\
\hline \multirow[t]{4}{*}{ Stage of disease } & I & 23 & 8.6 \\
\hline & II & 69 & 25.7 \\
\hline & III & 77 & 28.7 \\
\hline & IV & 99 & 36.9 \\
\hline \multirow[t]{4}{*}{ Duration of chemotherapy } & Duration mean \pm SD & Range from $1-48$ week & $\mathrm{s}, 10.3 \pm 6.3$ weeks \\
\hline & Less than 4 weeks & 34 & 12.7 \\
\hline & 5-12 weeks & 149 & 55.6 \\
\hline & More than 13 weeks & 85 & 31.7 \\
\hline \multirow[t]{3}{*}{ Purpose of chemotherapy } & Neo-adjuvant & 15 & 5.6 \\
\hline & Adjuvant & 157 & 58.6 \\
\hline & Palliative/recurrence & 96 & 35.8 \\
\hline \multirow[t]{3}{*}{ Regimen of chemotherapy } & Single agent & 88 & 32.8 \\
\hline & 2 combinations & 99 & 36.9 \\
\hline & $>2$ combinations & 81 & 30.2 \\
\hline
\end{tabular}

and "Self-distraction" $(6.0 \pm 1.8)$. The less common 5 coping strategies used by respondents were "Behavioral disengagement" (2.6 \pm 1.3$)$, "Denial" $(2.7 \pm 1.4)$, "Selfblame" $(2.8 \pm 1.3)$ and "Substance use" $(3.5 \pm 1.3)$.

Looking into the coping strategies used most by cancer patients according to proportion, problem-focused coping strategies was the highest used among the respondents, compared to emotion-focused coping strategies with 4.9 percent for "Humor" to 59.7 percent for "Religion" (rating in "doing this a lot). In Emotion-focused coping strategies, even though respondents rated from 3.7 percent for "Behavioral disengagement" to 48.9 percent for "Selfdistraction" (rating "Doing this a lot), the proportion of each dimension is small.

The association between categories of coping strategies problem-focused and emotion-focused between characteristics of cancer patients conducted (Table 4). Problem-focused coping strategies showed a significant association in sex $(\mathrm{p}=0.013)$ where female $(45.85 \pm 9.91)$ is higher mean score than male $(42.29 \pm 8.05)$ and education levels $(\mathrm{p}=0.000)$ where most being used by patients with university level (49.48 \pm 9.64$)$. Both problem-focused $(\mathrm{p}=0.007)$ and emotion-focused $(\mathrm{p}=0.011)$ found to be significant in age group where problem-focused

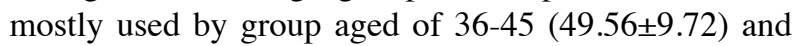
emotion-focused mostly used by group aged less than 35

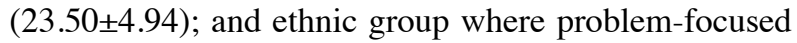
$(\mathrm{p}=0.013)$ mostly used among Malay $(51.49 \pm 8.51)$ and emotion-focused $(\mathrm{p}=0.001)$ mostly used among others-

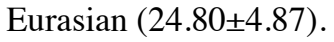


Symptom Experiences and Coping Strategies among Multi-Ethnic Solid Tumor Patients Undergoing Chemotherapy in Malaysia Table 2. Symptom Characteristics of Prevalence, Frequency, Severity and Distress among Cancer Population $(\mathbf{n}=\mathbf{2 6 8})$

\begin{tabular}{|c|c|c|c|c|c|}
\hline \multirow[t]{2}{*}{ Name of symptom } & & $\begin{array}{c}\text { Symptom } \\
\text { Prevalence }\end{array}$ & $\begin{array}{l}\text { Symptom } \\
\text { Frequency }\end{array}$ & $\begin{array}{l}\text { Symptom } \\
\text { Severity }\end{array}$ & $\begin{array}{c}\text { Symptom } \\
\text { Distress }\end{array}$ \\
\hline & Rank & $\mathrm{N}(\%)$ & $\mathrm{M} \pm \mathrm{SD}$ & $\mathrm{M} \pm \mathrm{SD}$ & $\mathrm{M} \pm \mathrm{SD}$ \\
\hline \multicolumn{6}{|l|}{$\overline{\text { Psychological group }}$} \\
\hline Difficulty in sleeping & 6 & $156(58.2)$ & $2.4 \pm 0.9$ & $2.2 \pm 0.9$ & $1.2 \pm 1.4$ \\
\hline Worrying & 9 & $139(51.9)$ & $2.2 \pm 0.8$ & $1.9 \pm 1$ & $0.9 \pm 1.1$ \\
\hline Feeling sad & 11 & $136(50.7)$ & $2.2 \pm 0.8$ & $1.8 \pm 0.8$ & $0.8 \pm 1.1$ \\
\hline Feeling nervous & 14 & $123(45.9)$ & $1.9 \pm 0.7$ & $1.7 \pm 0.6$ & $0.7 \pm 1.0$ \\
\hline Feeling Irritable & 15 & $120(44.8)$ & $2.3 \pm 0.9$ & $2 \pm 1$ & $0.8 \pm 1.1$ \\
\hline Difficulty concentrating & 17 & $114(42.5)$ & $1.9 \pm 0.7$ & $1.5 \pm 0.7$ & $0.7 \pm 1.0$ \\
\hline \multicolumn{6}{|l|}{ High Physical group } \\
\hline Lack of energy & 1 & $236(88.1)$ & $2.5 \pm 0.9$ & $2.1 \pm 0.9$ & $1.8 \pm 1.3$ \\
\hline Dry mouth & 2 & $201(75.0)$ & $2.4 \pm 0.9$ & $1.9 \pm 0.8$ & $1.2 \pm 1.1$ \\
\hline Feeling drowsy & 4 & $180(67.2)$ & $2.5 \pm 0.8$ & $2 \pm 0.8$ & $1.1 \pm 1.1$ \\
\hline Lack of appetite & 5 & $161(60.1)$ & $2.6 \pm 0.9$ & $2.2 \pm 0.9$ & $1.3 \pm 1.4$ \\
\hline Nausea & 7 & $156(58.2)$ & $2.1 \pm 0.9$ & $1.9 \pm 0.9$ & $1.0 \pm 1.2$ \\
\hline Change in the way food tastes & 8 & $150(56.0)$ & $\mathrm{NA} \pm-$ & $2.2 \pm 1.0$ & $1.1 \pm 1.3$ \\
\hline Pain & 10 & $137(51.1)$ & $2.0 \pm 0.9$ & $1.9 \pm 0.9$ & $1.0 \pm 1.2$ \\
\hline Dizziness & 18 & $113(42.2)$ & $2.0 \pm 0.9$ & $1.6 \pm 0.8$ & $0.6 \pm 0.9$ \\
\hline Weight loss & 19 & $112(41.8)$ & $\mathrm{NA} \pm-$ & $1.8 \pm 0.9$ & $0.6 \pm 1.0$ \\
\hline Constipation & 20 & $103(38.4)$ & $\mathrm{NA} \pm-$ & $2.1 \pm 1.0$ & $0.9 \pm 1.3$ \\
\hline Vomiting & 22 & $91(34)$ & $2.2 \pm 1.1$ & $2.2 \pm 1.1$ & $0.7 \pm 1.2$ \\
\hline Feeling bloated & 24 & $89(33.2)$ & $2.3 \pm 0.9$ & $1.7 \pm 0.8$ & $0.6 \pm .10$ \\
\hline \multicolumn{6}{|l|}{ Low Physical group } \\
\hline Numbness/tingling in hands/feet & 16 & $120(44.8)$ & $2.2 \pm 0.9$ & $1.9 \pm 0.9$ & $0.7 \pm 1.0$ \\
\hline Hair loss & 3 & $182(67.9)$ & $\mathrm{NA} \pm-$ & $2.9 \pm 1.1$ & $1.3 \pm 1.4$ \\
\hline Changes in skin & 12 & $131(49.0)$ & $\mathrm{NA} \pm-$ & $1.8 \pm 0.8$ & $1.1 \pm 1.2$ \\
\hline Cough & 13 & $127(47.4)$ & $1.8 \pm 0.7$ & $1.6 \pm 0.6$ & $0.7 \pm 1.0$ \\
\hline "I don't look like myself" & 21 & $101(37.7)$ & $\mathrm{NA} \pm-$ & $2.3 \pm 1.0$ & $0.8 \pm 1.3$ \\
\hline Mouth sores & 23 & $89(33.2)$ & $\mathrm{NA} \pm-$ & $2.1 \pm 0.9$ & $0.7 \pm 1.2$ \\
\hline Sweats & 25 & $84(31.3)$ & $2.0 \pm 0.9$ & $1.5 \pm 0.7$ & $0.3 \pm 0.6$ \\
\hline Diarrhea & 26 & $81(30.2)$ & $2.0 \pm 0.9$ & $1.8 \pm 0.9$ & $0.5 \pm 0.9$ \\
\hline Shortness of breath & 27 & $81(30.2)$ & $2.0 \pm 0.8$ & $1.6 \pm 0.8$ & $0.4 \pm 0.9$ \\
\hline Itching & 28 & $74(28.0)$ & $2.0 \pm 0.7$ & $1.8 \pm 0.8$ & $0.4 \pm 0.9$ \\
\hline Difficulty Swallowing & 29 & $60(22.4)$ & $2.3 \pm 1$ & $1.9 \pm 0.9$ & $0.4 \pm 0.9$ \\
\hline Problems with urination & 30 & $59(22.0)$ & $2.5 \pm 0.9$ & $2.1 \pm 1.0$ & $0.3 \pm 0.8$ \\
\hline Problems with sexual interest or activity & 31 & $49(18.3)$ & $2.5 \pm 1.1$ & $2.1 \pm 1.1$ & $0.3 \pm 0.8$ \\
\hline Swelling of arms or legs & 32 & $40(14.9)$ & $\mathrm{NA} \pm-$ & $1.9 \pm 1$ & $0.3 \pm 0.8$ \\
\hline
\end{tabular}

*NA indicates not applicable

Table 3. Mean Score and Percentage for Type of Coping Strategies Used by Cancer Patients $(\mathbf{n}=268)$

\begin{tabular}{|c|c|c|c|c|c|}
\hline \multirow{2}{*}{ Coping strategies used } & \multicolumn{5}{|c|}{ Rating Score (\%) } \\
\hline & $\mathrm{M} \pm \mathrm{SD}$ & $\begin{array}{c}\text { Haven't been doing } \\
\text { this at all }\end{array}$ & $\begin{array}{l}\text { Doing this } \\
\text { little bit }\end{array}$ & $\begin{array}{l}\text { Doing this } \\
\text { medium }\end{array}$ & $\begin{array}{l}\text { Doing this } \\
\text { a lot }\end{array}$ \\
\hline \multicolumn{6}{|l|}{ Problem-focused: } \\
\hline Religion & $6.5 \pm 1.8$ & 6.3 & 12.3 & 21.6 & 59.7 \\
\hline Acceptance & $6.4 \pm 1.6$ & 3.4 & 10.4 & 32.5 & 53.7 \\
\hline Use of emotional support & $6.3 \pm 1.7$ & 5.2 & 7.8 & 32.8 & 54.1 \\
\hline Use of instrumental support & $6.1 \pm 1.8$ & 5.2 & 15.7 & 29.1 & 50 \\
\hline Positive reframing & $6.0 \pm 1.6$ & 3.7 & 14.6 & 35.1 & 46.6 \\
\hline Active coping & $5.1 \pm 2.0$ & 14.9 & 27.6 & 25.7 & 31.7 \\
\hline Planning & $4.8 \pm 2.0$ & 16.4 & 29.9 & 29.1 & 24.6 \\
\hline Humor & $3.6 \pm 1.5$ & 37.7 & 32.1 & 25.4 & 4.9 \\
\hline \multicolumn{6}{|l|}{ Emotion-focused: } \\
\hline Self-distraction & $6.0 \pm 1.8$ & 6 & 13.4 & 31.7 & 48.9 \\
\hline Venting & $4.3 \pm 1.7$ & 21.6 & 32.5 & 32.8 & 13.1 \\
\hline Substance use & $3.5 \pm 1.3$ & 90.7 & 1.9 & 4.5 & 3 \\
\hline Self-blame & $2.8 \pm 1.3$ & 6.6 & 22.8 & 7.8 & 3.4 \\
\hline Denial & $2.7 \pm 1.4$ & 67.9 & 19.8 & 8.6 & 3.7 \\
\hline Behavioral disengagement & $2.6 \pm 1.3$ & 73.5 & 18.7 & 4.1 & 3.7 \\
\hline
\end{tabular}


Table 5. Pearson's r Correlation of Coping Strategies with Physical Symptom (PHYS), Psychological Distress (PSYCH) and Global Distress Index (GDI) $(\mathbf{n}=\mathbf{2 6 8})$

\begin{tabular}{lcccccc}
\hline Categories of coping strategies & \multicolumn{2}{c}{ PHYS } & \multicolumn{2}{c}{ PSYCH } & \multicolumn{2}{c}{ GDI } \\
\hline & $\mathrm{r}$ & P-value & $\mathrm{r}$ & P-value & $\mathrm{r}$ & P-value \\
Emotion-focused & $0.431^{*}$ & 0.000 & $0.424^{*}$ & 0.000 & $0.435^{*}$ & 0.000 \\
Problem-focused & 0.147 & 0.056 & 0.093 & 0.129 & 0.133 & 0.059 \\
\hline
\end{tabular}

*Correlation is significant at the 0.01 level (2-tailed)

Table 4. The Association between Categories of Coping Strategies Problem-Focused and Emotion-Focused between Characteristics of Cancer Patients $(n=268)$

\begin{tabular}{lcc}
\hline Characteristics & $\begin{array}{c}\text { Problem-focused } \\
(\mathrm{M} \pm \mathrm{SD})\end{array}$ & $\begin{array}{c}\text { Emotion-focused } \\
(\mathrm{M} \pm \mathrm{SD})\end{array}$ \\
\hline Sex (P-value)** & 0.013 & 0.917 \\
Male & $42.29 \pm 8.05$ & $20.94 \pm 5.17$ \\
Female & $45.85 \pm 9.91$ & $21.02 \pm 4.81$ \\
Age (P-value)** & 0.007 & 0.011 \\
$<35$ & $48.23 \pm 10.75$ & $23.50 \pm 4.94$ \\
36-45 & $49.56 \pm 9.72$ & $21.84 \pm 4.78$ \\
46-55 & $44.92 \pm 9.72$ & $21.09 \pm 5.09$ \\
56-65 & $42.95 \pm 8.90$ & $20.60 \pm 3.99$ \\
$>$ 66 & $43.97 \pm 8.83$ & $19.44 \pm 5.28$ \\
Education levels (P-value)** & 0.000 & 0.763 \\
No formal education & $42.69 \pm 6.43$ & $19.61 \pm 2.36$ \\
Primary school & $40.92 \pm 8.45$ & $20.82 \pm 4.80$ \\
Secondary school & $45.56 \pm 9.69$ & $21.34 \pm 4.79$ \\
College/Institute & $48.74 \pm 10.39$ & $21.00 \pm 6.94$ \\
University & $49.48 \pm 9.64$ & $20.69 \pm 3.72$ \\
Ethnic Group (P-value)** & 0.000 & 0.001 \\
Malay & $51.49 \pm 8.51$ & $22.10 \pm 3.80$ \\
Chinese & $42.96 \pm 9.32$ & $20.16 \pm 4.69$ \\
Indian & $44.60 \pm 9.00$ & $23.10 \pm 6.11$ \\
Others -Eurasian & $46.80 \pm 3.11$ & $24.80 \pm 4.87$ \\
\hline
\end{tabular}

Relationship between coping strategies used with physical symptom distress and psychological symptom distress

In Table 5, there was no significant relationship found between problem-focused coping strategies with physical symptom distress $(\mathrm{r}=0.147, \mathrm{p}=0.056)$ and psychological symptom distress $(\mathrm{r}=0.093, \mathrm{p}=0.129)$. There were significant relationships found between emotionfocused coping strategies and physical symptom distress ( $\mathrm{r}=0.431, \mathrm{p}=0.000)$; and psychological symptom distress $(r=0.424, p=0.000)$ but the strength of these relationships was moderate. This indicated that respondents who had increased physical and psychological symptom distress tended to use emotion-focused coping strategies.

\section{Discussion}

The finding of this study indicated that although these patients experienced a high number of symptoms, they are able to control and manage the symptoms accordingly. This is probably due to information given by nurses and doctors to patients about the side-effects of chemotherapy and effective management of these side-effects at each of cycle of chemotherapy. The patients reported a mean of 14 symptoms, ranging from 0 to 30 , which were higher

compared to previous studies by other researchers (Kim et al., 2009). This could be due to the variety of cancers included in this study and type of drugs received by patients. This finding supports the need for oncology nurses to continue to focus on symptoms management as a way to improve the quality of life of cancer patients undergoing chemotherapy.

The 10 most predominant symptoms when ranked according to characteristics were lack of energy, difficulty sleeping, lack of appetite, change in the way food tastes and hair loss, where the lack of energy was the highest prevalent symptom found in this study, which was consistent with the review findings by other researchers (Kim et al., 2009), and was also found to be the most prevalent symptoms in other 18 studies. The majority of the patients were breast cancer patients receiving moderate to highly emetogenic chemotherapy that also caused alopecia. These explain the most severe symptom experienced of hair loss reported in symptoms severity in this study. Similarly, the most common symptoms causing distress to patients in this study were hair loss, lack of appetite, difficulty in sleeping, lack of energy and dry mouth. This suggests that the severity of a symptom has a greater impact on distress level compared to the frequency of a symptom. Thus, it is important for health professionals to focus on this issue.

In terms of coping strategies, majority of the patients in this study tended to use a mixture of coping strategies: sub-dimensions of problem-focused coping strategies and emotion-focused coping strategies. This finding is consistent with the theory of Lazarus and Folkman that coping is a changing process in accordance with the situation and its appraisal (Lazarus and Folkman, 1984; Lazarus, 1993). Problem-focused strategies were more frequently used than emotion-focused strategies in this study which also similar to those reported by several previous researchers (Ben-Zur et al., 2001; Gilbar and Zusman, 2007; Wang et al., 2012; Butow et al., 2013; Price et al., 2013; Tuncay, 2014 ). Individuals have been reported to use problem-focused strategies more when they perceive they can alter the undesirable situation, and use emotion-focused strategies when there are few modifiable personal factors to change the situation (Lazarus,1993). However, other studies have reported emotion-focused coping strategies being more commonly used than problem-focused strategies (Zabalegui, 1999; Kim et al., 2002; Tan, 2007; Genc and Tan 2011). This inconsistency may be due to differences in the cultural background of patients studied or from a possible problem of the sample being generalized. Coping is a multidimensional concept where individual perception can be affected by an individual's beliefs and values (Lazarus and Folkman, 1984). The effect of cultural context on the coping strategies used by individuals with certain ethnic 
Symptom Experiences and Coping Strategies among Multi-Ethnic Solid Tumor Patients Undergoing Chemotherapy in Malaysia

heritage may not be wholly excluded.

In this study, only emotion-focused coping strategies were found to be correlated with physical distress and psychological distress. This indicates that patients choose emotion-focused strategies when there is an increase of distress level. Kuo and Ma (2002) and Tuncay (2014) reported a similar finding. They found that the frequency of emotion-focused strategies used was positively correlated with physical symptom distress, overall and individual psychological symptom distress score $(\mathrm{p}<.05)$. The findings of this study support the notion advanced by Lazarus and Folkman (1984); that is, the frequency of use of the different coping strategies is not necessarily related to their effectiveness. Emotion-focused strategies, consisting of four negative approaches, were used more often than problem-focused strategies, which consist of more positive approaches when patient's distress level is increased. This fact is consistent with the theory that emotion-focused strategies are more helpful than problemfocused ones when little can be done about the stressful situation (Lazarus and Folkman, 1984).

The higher odds of high physical symptom distress, and psychological symptom distress in good performance status (ECOG 0-1) reported in this study was contradictory to the findings by other studies (Portenoy et al.,1994; Portenoy et al., 1994; Akin et al., 2010), which reported that patients with poor performance status (KPS score $<80$ ) had significantly worse scores of symptom distress than patients with performance score of more than 80 . The lower level of physical symptom, and psychological symptom distress observed in patients with poor performance status (ECOG 2-3) is incongruent with the fact that patients with poor performance status are not physically fit and sometimes need assistance to help them in daily activities. Patients who are less physically fit were probably screened by the oncologist first and were offered limited dosage of chemotherapy with less toxicity. Another probability was that patients with poor performance status may have used more coping strategies to overcome their distress. Therefore, further study should also look into the association between patients' performance status and their coping strategies.

Further study with longitudinal or experimental designs with different cohort groups using random selection methods is desirable to examine coping patterns of patients with cancer more clearly. Based on the outcome of the study, further improvement in the current patient management particularly in the delivery of oncology services is recommended. A Self-Care Diary as suggested by Nail et al. (1991) composed of all side effects of chemotherapy along with a list of self-care activities, may be useful to patients. The establishment of symptoms management groups among nurses, and collaboration with other health-care providers such as dietitians, psychologists, oncologists, and social workers may also help patients in improving their experience while undergoing chemotherapy.

In conclusion, this study has examined on the symptom prevalence and concurred that side effects among cancer patients was relatively high. Psycho-oncology support program are needed to enhance the services such as providing spiritual therapy, or mind therapy to assist patients to cope with the symptom distress and improve the quality of life. It is also important for the nurses to give individualized nursing care to every patient before starting the chemotherapy and during subsequent chemotherapy to ensure that their side effects are manageable.

\section{References}

Akin S, Can G, Aydiner A, et al (2010). Quality of life, symptom experience and distress of lung cancer patients undergoing chemotherapy. Eur J Oncol Nurs, 14, 400-9.

Ben-Zur H, Gilbar O, Lev S (2001). Coping with breast cancer: patient, spouse, dyad models. Psychosom Med, 63, 32-9.

Butow P, Price M, Bell M, et al (2013). Quality of life, Distress and coping in women with ovarian cancer: a population based, longitudinal study. Psycho-oncology, 22, 44-5.

Cancer Facts \& Figures (2014). Retrieved $6^{\text {th }}$ November, 2014, from http://www.cancer.org/research/cancerfactsstatistics/ cancerfactsfigures2014/

Cancer Research Initiatives Foundation. (2014). Retrieved $6^{\text {th }}$ November, 2014, from http://carif.com.my/?page_id=3872

Carver CS (1997). You want to measure coping but your protocol's too long: consider the brief COPE. Int J Behav Med, 4, 92-100.

Chan C, Azman W, Mastura MY, et al (2014). Default of cancer treatment is associated with desire for psychological support. J Clin Oncol, 32, 5.

Cheng KKF, Eric MC, Wong MA, et al (2009). Measuring the Symptom Experience of Chinese Cancer Patients: A Validation of the Chinese Version of the Memorial Symptom Assessment Scale. J Pain Symptom Manage, 37, 44-57.

Currier DR (1984). Elements of research in physical therapy. Baltimore: Williams \&Wilkins, 166-67.

Dedert E, Lush E, Chagpar A, et al (2012). Stress, coping, and circadian disruption among women awaiting breast cancer surgery. Ann Behav Med, 44, 10-20.

Dupuis L, Ethier M-C, Tomlinson D, et al (2012). A systematic review of symptom assessment scales in children with cancer. BMC Cancer, 12, 1-6.

Engvall G, Skolin I, Mattson E, et al (2011). Are nurses and physicians able to assess which strategies adolescents recently diagnosed with cancer use to cope with disease-and treatment-related distress? Support Care Cancer, 19, 605-11.

Francoeur RB (2005). The relationship of cancer symptoms clusters to depressive affect in the initial phase of palliative radiation. J Pain Symptom Manage, 29, 130-155.

Genc F, Tan M (2011). Symptoms of patients with lung cancer undergoing chemotherapy and coping strategies. Cancer Nurs, 34, 503-9.

Gilbar O, Zusman A (2007). The correlation between coping strategies, doctor-patient/spouse relationships and psychological distress among women cancer patients and their spouses. Psychooncol, 16, 1010-18.

Gunusen NP, Ínan FŞ, Üstun B (2013). Experiences of Turkish women with breast cancer during the treatment process and facilitating coping factors. Asian Pac J Cancer Prev, 14, 3143-49.

Horney DJ, Smith HE, McGurk M, et al (2011). Associations between quality of life, coping styles, optimism, and anxiety and depression in pretreatment patients with head and neck cancer. Head Neck, 33, 65-71.

Jacobsen PB, Donovan KA, Vadaparampil, ST, et al (2007). Systematic review and meta-analysis of psychological and activity-based interventions for cancer-related fatigue. Health Psychol, 26, 660-7. 


\section{Nor Aziyan Yahaya et al}

Kim HS, Yeom HA, Seo YS, et al (2002). Stress and coping strategies of patients with cancer: A Korean study. Cancer Nurs, 25, 425-31.

Kim JE, Dodd MJ, Aouizerat BE, et al (2009). A Review of the prevalence and impact of multiple symptoms in oncology patients. J Pain Symptom Manage, 37, 715-36.

Kuo TT, Ma FC (2002). Symptom distresses and coping strategies in patients with non-small cell lung cancer. Cancer Nurs, 25, 309-17.

Lazarus RS (1993). Coping theory and research: Past, present and future. Psychosom Med, 55, 234-47.

Lazarus RS, Folkman S (1984). Stress, Appraisal, and Coping. New York: Springer.

Miaskowski C, Aouizerat BE, Dodd M, et al (2007). Conceptual issues in symptom clusters research and their implications for quality-of-life assessment in patients with cancer. J Natl Cancer Inst Monogr, 37, 39-46.

Nail LM, Jones LS, Greene D (1991). Use and perceived efficacy of self-care activities in patient receiving chemotherapy. Oncol Nurs Forum, 18, 883-7.

Price M, Bell M, Sommeijer D, et al (2013). Physical Symptoms, coping styles and quality of life in recurrent ovarian cancer: a prospective population-based study over the last year of life. Gynecol Oncol, 130, 162-8.

Portenoy RK, Thaler HT, Kornblith AB, et al (1994). Symptom prevalence, characteristics and distress in a cancer population. Qual Life Res, 3, 183-9.

Portenoy RK, Thaler HT, Kornblith AB, et al (1994). The Memorial symptom assessment scale: an instrument for the evaluation of symptom prevalence, characteristics and distress. Eur J Cancer, 30, 1326-36.

Roy S, Mallick S, Raza MW, et al (2014). Hematologic toxicity in patient undergoing radical anti-cancer therapy: a crosssectional aalysis of patients in an oncology ward in India. Asian Pac J Cancer Prev, 15, 3587-92.

Saniah AR, Zainal NZ (2010). Anxiety, Depression and coping strategies in breast cancer patients on chemotherapy. MJP Online Early, 2, 1-6.

Shoemaker LK, Estfan B, Induru R (2011). Symptom Management: An Important part of cancer care. Cleve Clin $J$ Med, 78, 25-34.

Tan M (2007). Social Support and Coping in Turkish Patients with Cancer. Cancer Nurs, 30, 498-504.

Tuncay T, Isikhan V (2010). Psychological symptoms, illnessrelated concerns and characteristics of relatives of Turkish patients with cancer. Asian Pac J Cancer Prev, 11,1659-67.

Tuncay T (2014). Coping and quality of life in Turkish women living with ovarian cancer. Asian Pac J Cancer Prev, 15 , 4005-12.

Walsh D, Donelly S, Rybicki L (2000). The symptoms of advanced cancer: Relationship to age, gender, and performance status in 1,000 patients. Support Care Cancer, 8, 175-9.

Wang X, Wang S-S, Peng R-J, et al (2012). Interaction of coping styles and psychological stress on anxious and depressive symptoms in chinese breast cancer patients. Asian Pac J Cancer Prev, 13, 1645-49.

Weeks JC, Catalano PJ, Cronin A et al (2012). Patients' expectations about effects of chemotherapy for advanced cancer. $N$ Engl J Med, 367, 1616-25.

Yoo GJ, Levine EG, Pasick R (2014). Breast cancer and coping among women of color: a systematic review of the literature. Support Care Cancer, 22, 811-24.

Yusoff N, Low WY, Yip CH (2009). Reliability and validity of the Malay version of brief COPE scale: a study on Malaysian women treated with adjuvant chemotherapy for breast cancer. Malays J Psych, 18, 27-35.
Zabalegui A (1999). Coping strategies and psychological distress in patients with advanced cancer. Oncol Nurs Forum, 26, 1511-18.

Zabalegui A, Sanchez S, Sanchez PD, et al (2005). Nursing and cancer support group. J Adv Nurs, 51, 369-81.

Zainal N, Hui K, Hang T, et al (2007). Prevalence of distress in cancer patients undergoing chemotherapy. Asia Pac J Clin Oncol, 3, 219-23. 